\title{
Dr. Wolfgang Eßer bleibt Chef der Vertragszahnärzte
}

\begin{abstract}
Die Vertreterversammlung der Kassenzahnärztlichen Bundesvereinigung (KZBV) hat im März in Berlin ein eindeutiges Votum abgegeben: Einstimmig wählten die Delegierten erneut Dr. Wolfgang Eßer zum hauptamtlichen Vorsitzenden des KZBV-Vorstandes. Seine neuen Stellvertreter sind Dr. Karl-Georg Pochhammer aus Berlin und Martin Hendges aus Köln.
\end{abstract}

Reibungsloser hätte die Wahl eines Vorstandes kaum laufen können. Als Dr. Wolfgang Eßer für die Wiederwahl zum Vorstandsvorsitzenden der KZBV vorgeschlagen wurde, reagierten die Delegierten mit Beifall. Einen Gegenkandidaten oder eine Aussprache gab es nicht. Wie anerkannt Eßer in der Zahnärzteschaft ist, machte der Vorsitzende der Vertreterversammlung, Dr. Karl-Friedrich Rommel, bereits vor der Wahl deutlich und lobte seine erfolgreiche Arbeit in der vergangenen Legislaturperiode: „Wolfgang Eßer hat Visionen und ist immer zur schwierigen Umsetzung seiner Visionen geschritten. “Diese Einschätzung spiegelt das eindeutige Wahlergebnis wider. Der 62-jährige Zahnarzt aus Mönchengladbach bleibt damit für die nächste fünfährige Amtsperiode Chef der 53.000 Vertragszahnärztinnen und Vertragszahnärzte in Deutschland.

\section{Eßer bezeichnet Hendges als „Hoffnungsträger"}

Erstmals in den Vorstand gewählt wurden seine Stellvertreter Dr. Karl-Georg Pochhammer, frisch gewählter Vorstandsvorsitzender der KZV Berlin, sowie Martin Hendges, stellvertretender KZV-Chef in Nordrhein. Auch für die beiden Stellvertreter votierte das Gremium sehr geschlossen. Gegenkandidaten gab es nicht.

Den 53-jährigen Hendges bezeichnete Eßer als „Hoffnungsträger dieser und weiterer Legislaturperioden“. Mit ihm verbinde er eine Zukunftsperspektive für die zahnärztliche Standes- politik. Beide Kandidaten hatte Eßer selbst vorgeschlagen. Er lobte ihr Engagement und ihre Einsatzbereitschaft für die Kollegen auf Bundesebene: „Niemand der beiden hätte es nötig, diesen Schritt zu tun, sie sind beide hauptamtlich in einer KZV verankert", sagte der KZBV-Chef. Umso mehr freue er sich, dass sie für die neuen Ämter zur Verfügung stehen.

Auf den neuen Vorstand warten jede Menge Themengebiete, die es zu bearbeiten gilt. Pochhammer hat sich bislang für die Berliner Vertragszahnärzte unter anderem um Finanzen, Haushalt und IT gekümmert. Hendges ist ein Vertragsspezialist und in der KZV Nordrhein für den Geschäftsbereich Sicherstellung verantwortlich.

Ihre Vorgänger, die langjährigen stellvertretenden Vorstandsvorsitzenden Dr. Jürgen Fedderwitz und Dr. Günther E. Buchholz hatten schon vor Monaten angekündigt, nicht erneut $\mathrm{zu}$ kandidieren.

\section{Auch VV-Vorsitzender bestätigt}

Vor der Wahl des Vorstandes bestätigten die Mitglieder Dr. Karl-Friedrich Rommel (KZV Thüringen) als Vorsitzenden der Vertreterversammlung (VV), das oberste Beschlussgremium der KZBV. Seine Stellvertreter sind Dr. Bernhard Reilmann (KZV Westfalen-Lippe) und Oliver Woitke (KZV Bremen).

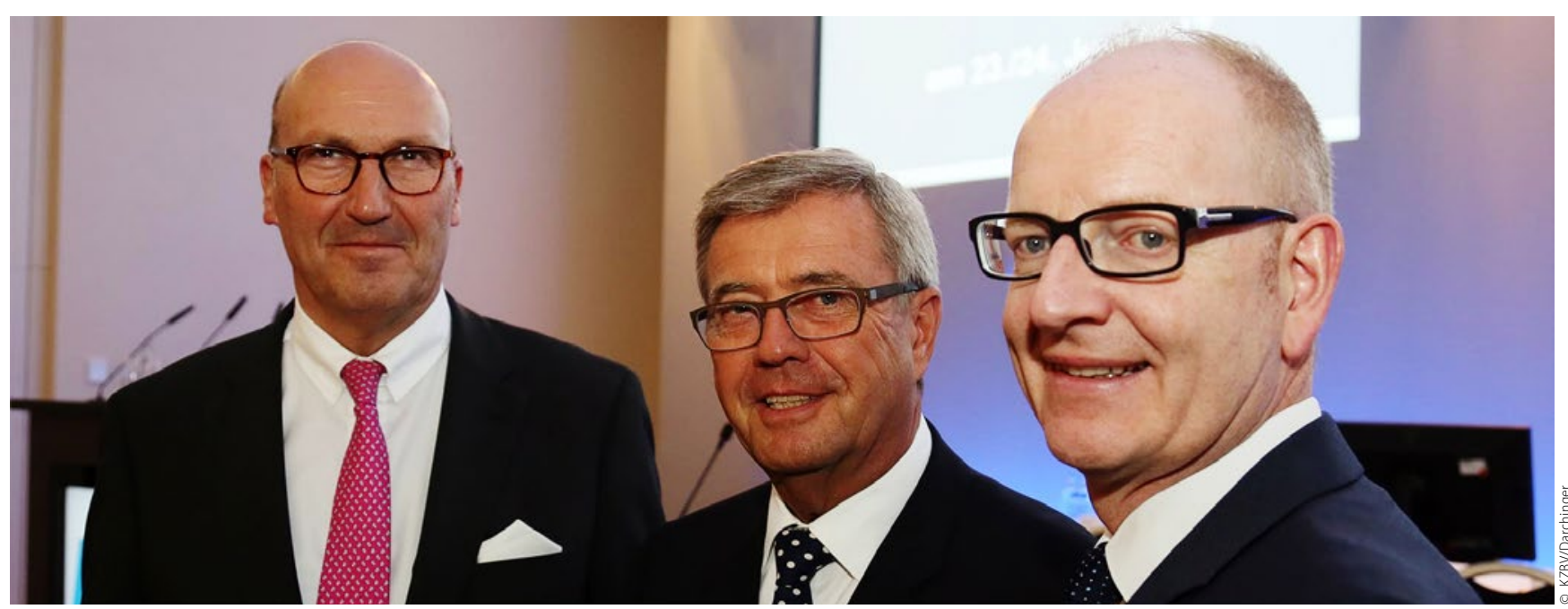

Vorstand der 15. Wahlperiode: Dr. Karl-Georg Pochhammer, Dr. Wolfgang Eßer und Martin Hendges (v. l. n. r.) 